\title{
Predatory behaviour of common kestrels (Falco tinnunculus) in the wild
}

\author{
Davide Csermely $\cdot$ Beatrice Bonati \\ Romano Romani
}

Received: 9 March 2008/ Accepted: 3 December 2008

(C) Japan Ethological Society and Springer 2009

\begin{abstract}
The predatory behaviour of eight wild adult common kestrels (Falco tinnunculus) was recorded during predatory tests carried out in the wild under controlled conditions. Those birds were offered one laboratory mouse each, which was restrained on a base, thereby simulating natural predation. The predatory sequence was recorded directly, but also video-taped. The sequence was rather homogeneous among the kestrels, with most kestrels starting the attack glide from a perch, then capturing the prey at high speed. The mouse was grabbed directly, upon landing; in one instance, however, it disentangled from the bird's foot and was captured after a few seconds. The target was usually grabbed at the shoulders or neck, or at the trunk. Soon after capture the kestrel flew to a distant perch, where it usually stroked the prey with one single peck, before starting ingestion, which began about 1 min time after prey grasping. Our results are the first to show the possibility of maintaining standardized conditions to study the predatory behaviour of birds of prey. As they are very similar to those obtained in previous tests carried out in captivity using rehabilitated kestrels, our results also confirm earlier ones showing that the kestrel's predatory behaviour is rather stereotyped-i.e. performed with limited variation - and that it can be studied reliably even in captivity.
\end{abstract}

D. Csermely $(\bowtie) \cdot$ B. Bonati

Dipartimento di Biologia Evolutiva e Funzionale, Sez. Museo di Storia Naturale, Università di Parma, Via Farini 90, 43100 Parma, Italy

e-mail: csermely@unipr.it

R. Romani

Dipartimento di Biologia Evolutiva e Funzionale, Sez. Biologia Animale, Università di Parma, Viale Usberti 11A, 43100 Parma, Italy
Keywords Behaviour description · Common kestrel · Falco tinnunculus · Predation - Predatory behaviour . Wildlife

\section{Introduction}

The common kestrel Falco tinnunculus, hereafter called "kestrel", is a widespread, medium-size raptor which preferentially resides in open areas, where it can scan at a distance for prey, relying on its sight, likely the most efficient sense of this bird. The kestrel is a generalist predator that feeds on a range of prey, including insects, amphibians, small reptiles and small mammals. Consequently, kestrels employ several hunting techniques, which vary between individuals (Riegert and Fuchs 2003) and according to climate and energy demand (Village 1990; Aparicio 2000). The kestrel has a sufficiently adaptable behaviour to allow it to easily reside in urban areas, where birds become an important prey (Salvati et al. 1999; Kübler et al. 2005).

During the cold season, prey are spotted and hunted from perches, a hunting technique that demands relatively little energy (Lihu et al. 2007). Such perches are visited at few minute intervals, whereas perches that enable wider areas to be scanned are changed less frequently (Village 1990; Shrubb 1993). Alternatively, kestrels sometimes search for prey by soaring, particularly over fairly flat ground and on hot days, when ground warming creates thermals suitable for hovering or wind hovering (Videler et al. 1983, cited by Village 1990). Wind hovering is a type of flapping flight punctuated by short glides; it is performed at a few metres of height above the ground and allows the kestrel to maintain its position relative to the ground, with continuous adjustments of a few centimetres. 
Irrespective of the hunting technique adopted, once the kestrel decides to capture its terrestrial prey, it performs a quick, fast glide, usually landing on the prey's body and seizes it with its foot. Soon after capture, the kestrel bites the prey once or twice. These bites have been reported to be the killing method, particularly when small mammals are preyed upon (e.g. Brown 1989; Village 1990), but Csermely et al. (1998) and Csermely and Bagni (2003) found that bites are nothing but a tool to damage the central nervous system and thereby limit the possibility of escape, while Csermely and Gaibani (1998) showed that the foot grabbing strength is compatible with inducing death by suffocation.

It can be challenging to study the hunting behaviour of raptors in the wild. Detailed, quantitative observations of hunting behaviour were first obtained by studying birds in captivity at the end of a rehabilitation period (Csermely et al. 1989, 1998; Csermely 1993, 1994; Csermely and Bagni 2003). It is possible that these studies were influenced by the captivity context and by the use of birds which had recovered from various kinds of injuries, although they were in perfect physical condition at the time of testing. Our aim was, therefore, to use a controlled, standardized approach to attract wild kestrels to prey on small mammals in order (1) to obtain data useful for comparison with eventual studies on the topic, with several variables controlled much better than in naturally occurring hunting attempts and (2) to be able to compare the behaviour recorded in this study with that previously reported in captivity tests in order to evaluate whether captive observations represent a reliable description of predatory behaviour in this species. We considered the data from Csermely (1993) as a reference for comparison with the captivity context because of the wide array of data recorded in this study. However, due to the great difference in context between the two studies, this comparison is only qualitative.

\section{Materials and methods}

The tests were carried out at five locations in the vicinity of Parma, northern Italy, in an intensively farmed agriculture area. The laboratory mouse Mus musculus domesticus (C3H strain with agouti fur) was used as prey. The mice used in trials were from a surplus group of animals bred in our department and destined to be euthanized.

In each test, the mouse acting as prey was kept in one of two types of portable bases: the first one was a plexiglas parabolic base, $75 \mathrm{~cm}$ in diameter, placed above and attached to a green plastic cylinder, $100 \mathrm{~cm}$ high. It had been spray-painted brown and green in order to mimic the colour of natural ground. The other structure used was a $1-\mathrm{m}^{2}$ piece of a $1-\mathrm{cm}$ wire mesh painted brown, with $10-\mathrm{cm}$ high sides. The floor and sides were covered by a polycarbonate sheet, with $15-\mathrm{cm}$-high sides to prevent the mouse from escaping. The polycarbonate was transparent and not dyed, but we painted a blue line at the upper edge of the sides to increase their visibility. Finally, the floor was covered with a jute sheet to create a natural appearance without limiting the mouse's movements. The floors of both structures were equipped with fresh grass, collected on site, food and a small amount of water. The tests were carried out at locations usually used by kestrels as hunting areas, such as fields adjacent to ditches as well as arable lands and meadows crossed by main lines, which are often used by kestrels as perches.

The activity of the mouse and the behaviour of the kestrel at capture were recorded both by direct visual observation and using a micro-colour wireless video-camera $(2.5 \times 3.5 \mathrm{~cm}$ in size $)$, powered by a $12-\mathrm{V}$ lead battery attached at the top of a 113-cm-high pole and about $90 \mathrm{~cm}$ distant from the test structure. The video-camera transmitted the image as radio-signal that was received by a receiver, which was connected by a cable to a colour monitor and a video-recorder, both located inside a car 20$50 \mathrm{~m}$ away. The receiver, monitor and video-recorder were all powered by a $12-\mathrm{V}$ car battery.

Each kestrel was used only once for the tests. Although we were unable to mark them individually, we were confident that each individual was tested only once because the test locations were quite far from one another [distance $6.0 \pm 2.4 \mathrm{~km}$ (mean \pm standard error, SE), range 2.5$20.1 \mathrm{~km}$ ], minimizing the likelihood that a kestrel could move from one location to another during the experimental period. Testing date and time of day for each kestrel are listed in Table 1. The birds were located and followed repeatedly during several days before testing, allowing us to determine that they were not wandering and following the reproductive season and to distinguish sub-adults from adult females. On the testing day, we put down the structure at a suitable site, placing one mouse above it and

Table 1 The gender of each tested kestrel, together with the date and time of test

\begin{tabular}{llll}
\hline Kestrel & Sex & Test date & Local time $(\mathrm{GMT}+1)$ \\
\hline 1 & F & 22 March & $10: 45$ \\
2 & M & 13 May & $17: 30$ \\
3 & F & 21 May & $18: 45$ \\
4 & M & 24 October & $10: 00$ \\
5 & F & 03 November & $11: 30$ \\
6 & F & 20 November & $13: 30$ \\
7 & M & 16 February & $13: 00$ \\
8 & M & 28 April & $11: 00$ \\
\hline
\end{tabular}

$F$ Female, $M$ male 
removing ourselves to the car immediately thereafter. The experimenter was then able to check the arrival of the kestrel and the movements of the mouse directly, either by watching with $8 \times 30$ binoculars or by looking at the monitor.

On the day of testing the experimenter surveyed the chosen area from a car, looking for flying or perched kestrels. As soon as the bird was located, and once the site had been determined to suitable for carrying on the test, the equipment was quickly set up and the experimenter returned to the car. Sometimes the kestrel flew for a few or several minutes, agitated by the human presence. In other instances, however, it remained motionless. In the first case, the test started when the kestrel was visually contacted again in the area around the experimenter, while in the second case the test started as soon as the mouse entered the test confinement. The tests were performed in daytime when kestrels are most active. The number of tests were kept to a minimum, but a sufficient number were performed to procure an adequate statistical sample, while at the same time sacrificing as few prey as necessary, as recommended by Still (1982); Huntingford (1984) and the Association for the Study of Animal Behaviour, Animal Behavior Society (2001).

We recorded the following behaviour parameters before prey capture: (1) frequency and latency from test starting of movements on the perch, preening and pre-capture flights; (2) total duration of preening. In addition, we recorded the following behavioural parameters related to prey capture: (3) latency to predation; (4) type of capture, i.e. direct (landing on the prey and grasping it immediately) or indirect (landing a few centimetres from the prey and grabbing it after a few steps); (5) which foot was used for grasping; (6) prey body side where grab occurred; (7) pecking frequency to the prey; (8) latency to ingestion (i.e. the time elapsed from capture to start of ingestion); (9) site where ingestion occurred.

The distances and heights of the kestrel from the prey were calculated considering structures of known length or height. Sky appearance was calculated subjectively as number of quarters covered by clouds (from $0=$ clear sky to $4=$ sky fully covered), while the air temperature was measured in degrees Celsius and wind velocity was measured on the Beaufort scale. Frequencies were statistically analysed using the chi-square component $z$ index (Bishop et al. 1975). Data presented are the mean $\pm \mathrm{SE}$, and the probability, set at $\alpha=0.05$, is two-tailed through-out.

The data used for comparison come from a study carried out by Csermely (1993) using wild kestrels temporarily kept in captivity and at the end of their rehabilitation period. They had been offered a live mouse of the same strain as that used in this study (for details of the procedures, the reader is referred to that publication).

\section{Results}

We tested a sample of eight adult kestrels, equally split between sexes; each kestrel performed one test. As no sexbias was recorded for any of the behaviour parameters considered, we did not segregate the results based on sex. Three tests were carried out using the parable base, whereas the wire mesh base was used in the other five tests. We did not record any difference in the several behaviour parameters considered between the bases and, therefore, we decided to merge the results, regardless of the base type.

The tests were carried out on days of good weather; only one test had initially moderate fog, which had disappeared by the time the kestrel attacked the prey. Sky cover was $1.88 \pm 0.64$ and temperature was $17.75 \pm 2.31^{\circ} \mathrm{C}$ (range $10-28^{\circ} \mathrm{C}$ ), while wind velocity on the Beaufort scale was $1.94 \pm 0.71$ (range 0-5-6). The latency to predation, i.e. the time elapsed from mouse appearance on the base or kestrel arrival at the site while the prey was already on the base and the capture, was $913.1 \pm 233.6 \mathrm{~s}$.

After detecting the mouse, none of the perched kestrels moved on their perches. Nevertheless, they performed $1.63 \pm 0.78$ flights each above the prey, with a mean latency of $740.3 \pm 505.7 \mathrm{~s}$ (range $0-1740 \mathrm{~s}$ ). One of these scored a latency of $0 \mathrm{~s}$, starting to fly as soon as the mouse appeared.

Preening was recorded in two birds only, while perched at an estimated distance of $20-50 \mathrm{~m}$ and $10-20 \mathrm{~m}$ high, respectively. Both kestrels preened only once, with a latency of $675.0 \pm 660.0 \mathrm{~s}$ ( 15 and $1335 \mathrm{~s}$, respectively) and a duration of $100.5 \pm 34.5 \mathrm{~s}$ (66 and $135 \mathrm{~s}$, respectively). All kestrels reacted to the prey with perch hunting, and a variety of perches were used, such as electricity cables or pylons, trees, poles, lamp-posts, hay-bales. Two kestrels started from electricity pylons. The several perches were $20-50 \mathrm{~m}$ distant from the prey, but in one case it was just $3 \mathrm{~m}$ away.

The birds performed the attack glide with a mean latency of $913.1 \pm 233.6 \mathrm{~s}$ (range 161-1920 s). No kestrel performed a hanging manoeuvre when attacking the mouse, whereas two birds hovered directly over the mouse, both for $30 \mathrm{~s}$ in duration. One of these birds gradually approached the mouse, but neither of these two kestrels preyed directly on the mouse; in fact, both went to perch nearby before carrying out the actual attack. The predatory attacks were mostly direct, i.e. the kestrel landed directly on the mouse gripping it at landing (seven tests out of eight: $z=1.500, P<0.05$ ). The only occurrence of indirect attack was when the mouse succeeded in freeing itself, as described below.

In half of the tests, kestrels grabbed the shoulders or neck of the mouse; in two tests, they grabbed the trunk 
$(z=0.577, P>0.05)$; it was impossible to ascertain exactly what happened in the remaining two tests. The peckings, usually a bite more than a peck, occurred in every test, with a mean frequency of $2.75 \pm 1.15$. After grasping the mouse, six of eight kestrels $(z=1.000$, $P<0.05)$ pecked it once; the remaining birds grasped the mouse without interrupting their flight, nonetheless pecking with eight strikes after perching.

Capture was particularly fast, which caused difficulty in discerning the particulars, even after analysing the frameby-frame video recording. The kestrel sometimes also put itself between the prey and the video-camera, preventing a detailed analysis. In one case, however, it was possible to determine clearly that the bird grabbed the mouse at the shoulders, without touching the ground, using the right foot only. The kestrel then landed a few centimetres away using the left foot and continuing to have a firm hold on the prey. Immediately afterwards, the bird took-off flying to a nearby perch. In another test, the kestrel used the right foot as well to capture the mouse at the neck, but it evidently used even the left foot soon after, because when it left the base, without landing, it was clearly holding the mouse with both feet. One male performed a more complex capture. At the end of a direct attack, the kestrel failed in grasping it with any foot, due to the sudden reaction of the mouse, which succeeded in freeing itself and withdrawing a few centimetres. The kestrel, however, came back to the prey, this time being able to grasp it with the right foot. Four seconds elapsed from the failed initial grasp and the successful one. The kestrel pecked the prey immediately after the grasp. The left foot, initially used for balance at landing, was the one used for grasping as well, likely to provide enough thrust for take-off.

Prey ingestion occurred invariably far from the capture site, with this behaviour being related to the use of non-breeding kestrels; the latency of ingestion was $58.3 \pm 21.1 \mathrm{~s}$. One kestrel ingested the mouse about $20 \mathrm{~m}$ far from the predation site, four others $20-50 \mathrm{~m}$ away and one more than $50 \mathrm{~m}$ away. The remaining two kestrels flew very far, such that we could not identify the sites where they ingested the prey. The perching height was about $20 \mathrm{~m}$ for five of six birds $(z=1.155, P<0.05)$; the sixth bird perched on the ground.

We felt it was useful to compare our data with those obtained in similar tests performed in captivity using wild kestrels at the end of their rehabilitation period, in particular considering the data from Csermely (1993). The 18 birds which preyed on a laboratory mouse of the same strain as that in the present study performed very few $(0.17 \pm 0.17)$ movements on the perch soon after prey appearance. Such movements were mainly lateral movements along the perch, but sometimes kestrels also turned their bodies. Before the predatory attack glide, kestrels performed a mean flight frequency per test of $0.44 \pm 0.23$, usually starting from their perch and returning to it.

Captures were equally direct or indirect, almost always using one foot only (both feet were used once). In contrast to our tests, all kestrels in captivity remained standing where they blocked the mouse, while squeezing it with the foot. During that time period, which lasted $119.9 \pm 15.0 \mathrm{~s}$, they pecked the mouse mostly at the head, but sometimes also at the trunk, with a frequency of $14.00 \pm 2.00$ pecks. Most kestrels ingested prey on the ground near the capture location.

\section{Discussion}

Although our sample size was small, the consistent results of our predation tests suggest that predatory behaviour is generally not affected by the experimental context and is therefore reliable for a description of predation as occurs in nature. The kestrels did not move on the perch or preen in most tests, as has been noted in tests carried out in captivity with rehabilitated wild birds (Csermely 1993). Movements and preening are the more likely indications of the bird's motivational conflict, emphasized by the captivity context, particularly due to the necessarily short distance from the prey. Actually, in captivity, movements and preening were more frequent in birds facing a dead prey or in those refusing prey. In contrast, such a conflict is unlikely in the wild as it would be rather non-adaptive in front of a prey.

Both the kestrels in this study and those in captivity described by Csermely (1993) performed exploratory flights above the prey before attacking. Csermely hypothesized that their function in captivity was to better evaluate capture possibility. The observations in the wild of the study reported here confirm that interpretation: flights were performed in six of the eight tests, being either high and wide circles, low and tight circles or hovering. On the other hand, the two kestrels not performing flights were perched less than $30 \mathrm{~m}$ away from the prey and could well watch it anyway.

Predations were almost always performed by direct attack (seven of eight tests). The only instance when the attack was indirect, it was because the mouse disentangled itself from the kestrel's grip. Direct attacks show the necessity that the kestrel make a firm grab at the prey with the first attempt before the latter realizes the situation and tries to escape. This is different from the captivity context, where indirect attacks were as frequent as direct ones, likely because of the higher possibility to capture the mouse even without the necessity of landing on it.

Six kestrels of our study pecked the mouse only once, at the head or trunk, and two pecked eight times, at the trunk. They then left the capture location, flying to a high perch 
(all but one). This behaviour was not performed by kestrels in captivity; instead, the latter usually pecked the prey more than once and usually ingested it at the same location. It is likely that they realized that the captivity was a "threat-free" context, leading them to remain on the ground for relatively long time. In the wild, conversely, a perching bird is highly vulnerable when on the ground and, therefore, remains there for as short time as necessary while squeezing its terrestrial prey and aiding the grasp with pecks to the head in order to damage the central nervous system and reduce the possibility of the prey escaping (Csermely 1993; Csermely et al. 1998; Csermely and Bagni 2003).

Although our sample population was not large enough to allow a statistical analysis, it should be noted that our kestrels grabbed the mouse with either both feet or, more often, with one foot only, the right one. They later used both feet to hold the mouse while flying to the perch where ingestion occurred. The use of one foot for blocking the prey is likely caused by the necessity to use the other one for a firm balance on the ground (Csermely 2004), as our tests were performed offering a terrestrial prey. Conversely, the use of both feet for aerial prey transportation is a consequence of the necessity to have a firm grip on the prey to avoid losing it by falling.

Once perched, our kestrels waited approximately $60 \mathrm{~s}$ before starting ingestion, sometimes again pecking the prey. This is another similarity to observations in captivity by Csermely (1993), who noted the same time period elapsing before ingestion (latency to ingestion), during which more or less the same number of peckings were made. This result confirms previous interpretations (Csermely 1993; Csermely et al. 1998; Csermely and Gaibani 1998; Csermely and Bagni 2003) about kestrels delaying ingestion to after being certain of prey death. In our study, however, it was not possible to note the body part target of those pecks due to the perch distance from test location.

In conclusion, the predatory behaviour of the kestrel in the wild on a terrestrial prey is rather similar to that in captivity. The only recorded difference concerns the conflict behaviours before attacking, which were not performed in the wild, and the location where kestrels ingested the prey itself. The remaining aspects of the predatory sequence are very similar between the wild and captive situation, thereby confirming the stereotyped character of the entire predatory sequence (Csermely 1993).

The behaviours were the same when kestrels preyed on both types of structures used for the tests, confirming that the kestrel's behaviour sequence is not affected by the substrate where the prey is found and again emphasizing the rather stereotyped behaviour involved. Based on our observations, therefore, we conclude that, in general, it is possible to overcome the difficulty of studying predatory behaviour in the wild by setting up an experimental system; in particular, it would appear that the behaviour of the kestrel in the wild is the same as that observed in a captivity context.

Acknowledgments We thank the Parma Provincial Administration for permission to study the wild kestrels on its territory. We appreciate the improvements in English usage made by Jen Johnson through the Association of Field Ornithologists' program of editorial assistance, led by Daniel M. Brooks as well as the constructive comments and suggestions from two anonymous reviewers on an earlier version of the manuscript. The research was supported by the Italian Ministero dell'Università e della Ricerca.

\section{References}

Aparicio JM (2000) Differences in the diets of resident and nonresident kestrels in Spain. Ornis Fennica 77:169-175

Association for the study of animal behaviour, Animal Behavior Society (2001) Guidelines for the treatment of animals in behavioural research and teaching. Anim Behav 61:271-275

Bishop YMM, Fienberg SE, Holland PW (1975) Discrete multivariate analysis. Theory and practice. MIT Press, Cambridge

Brown L (1989) British birds of prey. Bloomsbury Books, London

Csermely D (1993) Duration of rehabilitation period and familiarity with the prey affect the predatory behaviour of captive wild kestrels, Falco tinnunculus. Boll Zool 60:211-214

Csermely D (1994) Does prey size affect predatory behaviour of kestrel? Avocetta 18:63-67

Csermely D (2004) Lateralisation in birds of prey: adaptive and phylogenetic considerations. Behav Process 67:511-520

Csermely D, Bagni L (2003) The predatory behaviour of common kestrels facing various types of prey. J Ethol 21:107-110

Csermely D, Gaibani G (1998) Is the foot squeezing pressure by two raptor species a tool used to subdue their prey? Condor 100:757763

Csermely D, Mainardi D, Agostini N (1989) The predatory behaviour of captive wild kestrels, Falco tinnunculus. Boll Zool 56:317320

Csermely D, Bertè L, Camoni R (1998) Prey killing by Eurasian kestrels: the role of the foot and the significance of bill and talons. J Avian Biol 29:10-16

Huntingford FA (1984) Some ethical issues raised by studies of predation and aggression. Anim Behav 32:210-215

Kübler S, Kupko S, Zeller U (2005) The kestrel (Falco tinnunculus L.) in Berlin: investigation of breeding biology and feeding ecology. J Ornithol 146:271-278

Lihu X, Jianjian L, Chunfu T, Wenshan H (2007) Foraging area and hunting technique selection of common kestrel (Falco tinnunculus) in winter: the role of perch sites. Acta Ecol Sinica 27:2160-2166

Riegert J, Fuchs R (2003) Individual hunting behaviour of urban kestrels (Falco tinnunculus). In: Proc 6th World Conf Birds Prey Owls. Budapest, p 1

Salvati L, Manganaro A, Fattorini S, Piattella E (1999) Population features of kestrels Falco tinnunculus in urban, suburban and rural areas in central Italy. Acta Ornithol 34:53-58

Shrubb M (1993) The kestrel. Hamlyn, London

Still AW (1982) On the number of subjects used in animal behaviour experiments. Anim Behav 30:873-880

Videler JJ, Weihs D, Daan S (1983) Intermittent gliding in the hunting flight of the kestrel Falco tinnunculus. J Exp Biol 102:12

Village A (1990) The kestrel. T\&AD Poyser, London 